\title{
CASE REPORT: HAIRY TERATOMATOUS CYST IN THE OCCIPITO-CEREBELLAR REGION*
}

\author{
BY \\ S. OBRADOR \\ Instituto de Neurocirugia, Madrid, Spain
}

Teratomas are extremely rare intracranial lesions and their frequency in the neurosurgical series of brain tumours is very low, only about $0.2 \%$ in the material of Harvey Cushing (1932), and in the large experience of Dandy (1945) no examples were recorded. Logue and Till (1952) reported seven cases and reviewed the literature, stressing the frequency of intracranial infection as a complication of this kind of tumour. The presence of hair within the cyst of the teratomas has been considered very uncommon and it is also very rare in those series of infants where the incidence of these tumours is higher (Ingraham and Bailey, 1946).

In our experience of more than 600 cases of brain tumour and other expansive intracranial lesions operated upon during the last seven years we have only a single instance of a cystic teratoma. We have considered it worthwhile to record this case because of some exceptional findings, such as the presence of a great amount of long hair within the cyst and the situation of the tumour in the cerebellooccipital region.

\section{Case Report}

A 25-year-old girl was admitted to the Institute of Neurosurgery complaining of symptoms related to increased intracranial pressure.

The symptoms started one and a half years before admission with headaches beginning in the suboccipital region and spreading upwards. There was some giddiness and sense of insecurity. The headache appeared in the mornings and increased in severity during the seven months before admission when it was accompanied by vomiting. The gait became very unsteady and there was also some lateral deviation. In the last month before admission she had noticed some irregular diplopia and progressive loss of vision.

On examination the patient was seen to be pale and thin but in fair general condition. In the scalp we found a small dimple in the occipital region, about $3.5 \mathrm{~cm}$. above the external occipital protuberance in the middle

*Case reported to the fifth annual meeting of the Spanish Neurological Society in Barcelona in December, 1953. line. There was a bald spot in this area the size of a finger's tip and a corresponding defect of the underlying bone. On enquiry the patient informed us that she had always had this dimple and did not connect it with the actual complaint. There was no pain or tenderness at the site. There was very marked papilloedema with secondary optic atrophy, and severe loss of vision with concentric reduction of the fields : she was barely able to count fingers at 1 metre. There was slight lateral and vertical nystagmus on conjugate deviation of the eyes. In the limbs there was moderate ataxy, tremor, and dysdiadokokinesia, if anything more marked on the left side, and the gait was unsteady. The examination otherwise was negative. Radiographs of the skull showed a small circular defect in the bone underlying the dimple in the occipital region, in addition to signs of increased intracranial pressure, e.g. convolutional thinning of the vault, enlargement of the sella, and erosion of the posterior clinoid processes.

Ventriculography revealed an obstructive lesion in the posterior fossa and a suboccipital exploration was carried out under general anaesthesia. A large cystic area was found in the upper part of the middle line of the cerebellum. The cyst contained a great amount of thick, dirty-yellow fluid and a surprising amount of hair in very long coils. The hair obtained from the interior of the cyst filled a $100 \mathrm{ml}$. cylinder and the length of the coils measured between 21 and $89 \mathrm{~cm}$. (Fig. 1). Once the interior of the cyst was evacuated we saw that the tumour capsule extended deeply and upwards. Relating the finding of a congenital type of tumour with the occipital dimple present since birth, we decided to combine an occipital flap with the usual suboccipital approach in order to complete the exposure. The superior longitudinal sinus appeared deviated to the right. The invaginated occipital skin and subcutaneous tissue were dissected around the skull defect, and finally working both above and below the tentorium we removed all this tissue from the skin dimple along the fibrous band which connected it with the cerebellar mass through an aperture in the tentorium. Figure 2 is a diagrammatic representation of the anatomical arrangements.

Dr. Morales made the histological diagnosis of a very complex teratomatous tumour with epidermoid epithelium in gland-like structures, with some hair. 


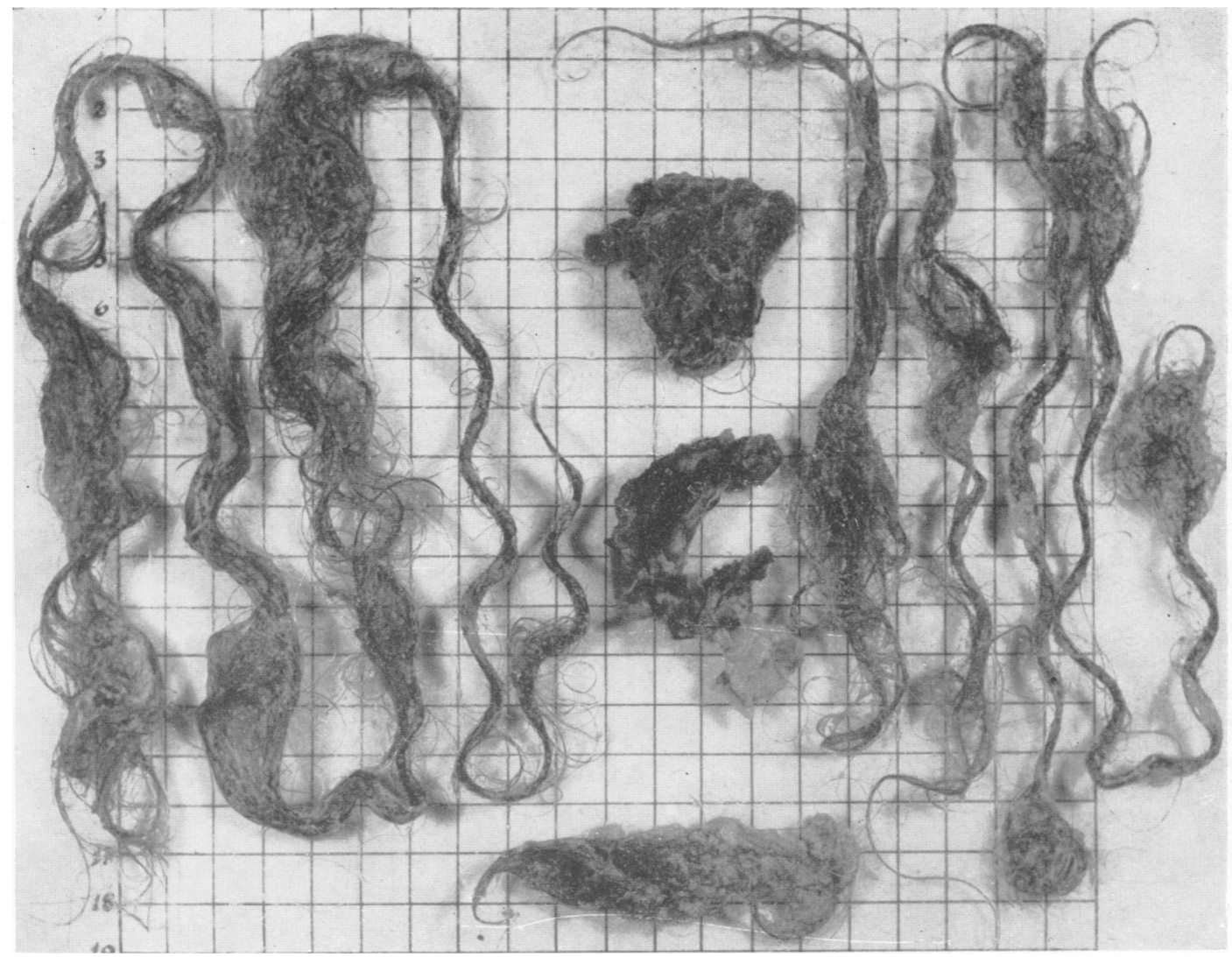

FIG. 1

Post-operatively there were no complications of significance, and frequent aspiration of subcutaneous fluid in the area of the right occipital flap was necessary only during the first few weeks. The cerebellar syndrome increased immediately after the opera'ion but

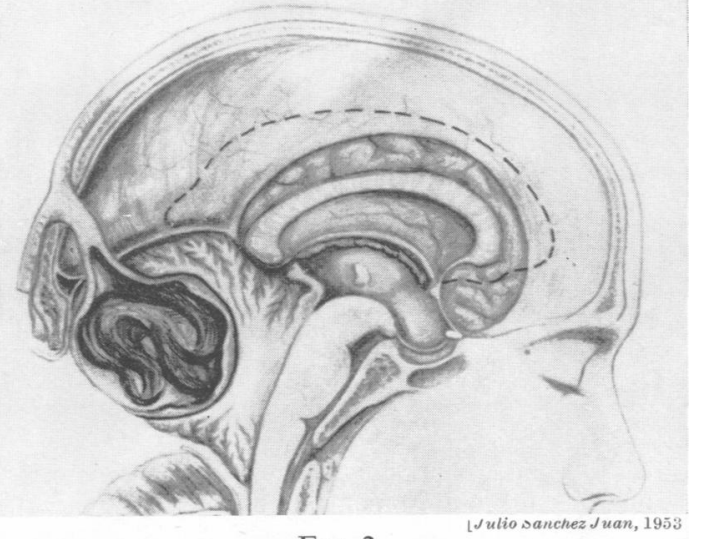

two months later it was regressing and the main residual disability was in the gait. The symptoms of increased intracranial pressure have disappeared and the papilloedema has subsided leaving a secondary optic atrophy.

\section{Summary}

A case is reported of a 25 -year-old girl with a clinical syndrome of a posterior fossa tumour produced by a teratomatous cyst of the middle line of the cerebellum which contained a great amount of hair in large coils up to $89 \mathrm{~cm}$. long. The tumour extended through an opening in the tentorium to the occipital region where there was a very small congenital bony defect. Combining in one stage the suboccipital approach with a supratentorial one the abnormal tissue was completely removed.

\section{REFERENCES}

Cushing, H. (1932). Intracranial Tumours. Thomas, Springfield, Ill. Dandy, W. E. (1945). "The Brain". In Practice of Surgery, ed. Lewis, D., vol. 12, chapter 1. Prior, Hagerstown, Maryland. Ingraham, F. D. and Bailey, O. T. (1946). J. Neurosurg., 3, 511. Logue, V., and Till, K. (1952). Journal of Neurology, Neurosurgery and Psychiatry, 15, 1. 